\title{
Лазеры в аналитической спектроскопии
}

М. А. Большов, д. Ф.-М.Н., Институт спектроскопии РАН, Троицк mbolshov@mail.ru
УДК 543.42

Статья получена 15.12.2019

Принята к публикации 20.01.2020

В основу статьи положен пленарный доклад автора на III Всероссийской конференции по аналитической спектроскопии. Приведен краткий обзор использования лазерного излучения в аналитической спектроскопии. Рассмотрены методы, основанные на резонансном селективном возбуждении свободных атомов аналита излучением лазеров с узкой спектральной шириной линии. Обсуждены проблемы, по которым методы лазерного селективного детектирования элементов уступили эмиссионной и масс-спектрометрии с использованием индуктивно связанной плазмы (ИСП-АЭС и ИСП-МС). Подробно рассмотрены методы прямого анализа твердых образцов с помощью лазерной абляции - испарения материала образца в фокальном пятне мощного лазерного импульса, сфокусированного на поверхности пробы. Описаны достоинства и ограничения лазерно-индуцированной эмиссионной спектроскопии (ЛИЭС) и комбинированного метода ЛА-ИСП-МС. В заключительной части обсуждается метод абсорбционной спектроскопии с перестраиваемыми диодными лазерами (ДЛАС). Сложилась достаточно широкая область аналитических задач, где успешно используется метод ДЛАС - от бесконтактной диагностики горячих зон до диагностики заболеваний по выдыхаемому воздуху пациента.

\section{Селективные методы лазерной спектроскопии}

В 70-90-х годах прошлого века в аналитическом сообществе возникла эйфория по поводу возможностей лазеров с перестраиваемой длиной волны генерации как новых источников резонансного излучения, которые могли бы обеспечить значительное повышение чувствительности элементного анализа. Действительно, узкая ширина спектра излучения лазеров и спектральная плотность мощности, превышающая на много порядков плотность мощности классических источников резонансного излучения типа ламп с полым катодом или безэлектродных разрядных ламп, являлись предпосылками для существенного роста чувствительности в определении элементов. В эти годы бурно развивались различные методы лазерной аналитической спектроскопии лазерно-индуцированная флуоресценция (LIF, ЛИФ), лазерная многофотонная ионизация (RIS), ионизация с лазерно-возбужденных уровней (лазерно-усиленная ионизация - LEI). Все эти методы были основаны на селективном возбуждении резонансного перехода (или ступенчатом возбуждении нескольких переходов, как в случае RIS) выбранного элемента с последующим детектированием либо флуоресценции возбужденного атома, либо регистрацией иона, образовавшегося в результате взаимодействия атома с резонансным полем (или полями) возбуждающего лазера.

Надежды на лазерные методы основывались на рекордно низких пределах обнаружения элементов в специально разработанных кюветах с регулируемой концентрацией определяемого элемента. Так, в кювете с регулируемой температурой минимальная концентрация свободных атомов $\mathrm{Na} 100$ атомов/ $\mathrm{cm}^{3}$ была зарегистрирована при температуре $-28^{\circ} \mathrm{C}$ методом LIF [1]. Концентрация свободных атомов $\mathrm{Pb} 250$ атомов/ см $^{3}$ была зарегистрирована в [2], причем на пороге определения в лазерном пучке находились в среднем 30 атомов свинца. Результаты этих экспериментов представлены на рис. 1. Надо отметить, что эти рекордные чувствительности в идеальных условиях специально разработанных кювет основывались на том обстоятельстве, что свободный атом аналита, попавший в лазерный пучок, может быть зарегистрирован с вероятностью близкой к единице. 
Еще в начале разработки лазерных методов применительно к анализу реальных образцов было понято, что условия модельных экспериментов с насыщенными парами свободных атомов существенно отличаются от таковых в реальных опытах с конкретными устройствами, переводящими анализируемый образец в атомарный пар (атомизаторами). Тепловое излучение нагретых частей атомизаторов, рассеяние возбуждающего лазерного излучения в атмосфере атомизаторов, далекая от 100\% вероятность атомизации аналита из пробы - все эти факторы значительно повысили границы определения минимальных концентраций широкого круга элементов лазерными методами. Тем не менее они по-прежнему значительно превосходили по чувствительности методы с классическими источниками резонансного излучения. Примером решения уникальных аналитических задач является детектирование ультра-малых содержаний тяжелых металлов в образцах глубинного льда и снега, отобранных в полярных регионах Земли [3, 4]. Методом LIF были измерены концентрации свинца в кернах льда, поднятых с различных горизонтов глубинной ( 900 м) скважины в Антарктиде. При достигнутых пределах определения 0,2 ppt содержание свинца в различные геологические эпохи варьировалось в диапазоне 0,3-30 ppt. Уникальность этих результатов состояла в малом требуемом объеме пробы (30 мкл) и экспрессности определения (примерно 5 мин на одно пробоопределение), что существенно превосходило эти параметры для альтернативного в то время метода масс-спектрометрии с изотопным разбавлением - 200 мл пробы и два пробоопределения за рабочий день (рис. 2).

Основная причина ухода резонансных методов лазерной спектроскопии из аналитической практики кроется в их принципиальной "одноэлементности". Длина волны возбуждающего лазера во всех перечисленных методах настраивается на частоту сильного резонансного перехода атомов одного элемента, и в одном цикле измерения определяется только этот элемент. Это коренным образом отличает резонансные лазерные методы от методов на базе индуктивно связанной плазмы (ИСП). И эмиссионный вариант ИСП-АЭС, и особенно метод масс-спектрометрии с ИСП (ИСП-МС) обеспечивают определение широкого набора элементов в одном цикле измерения. В конце прошлого - начале этого века бурное развитие методов на основе ИСП практически отодвинуло резонансную лазерную спектроскопию на периферию элементного анализа. Если основным преимуществом ИСП-АЭС над лазерными методами является возможность многоэлементного анализа, то ИСП-МС во многих случаях превосходит их по чувствительности определения. Высокие аналитические характеристики методов на базе ИСП обеспечили их успешную коммерциализацию. Сегодня ряд фирм выпускает
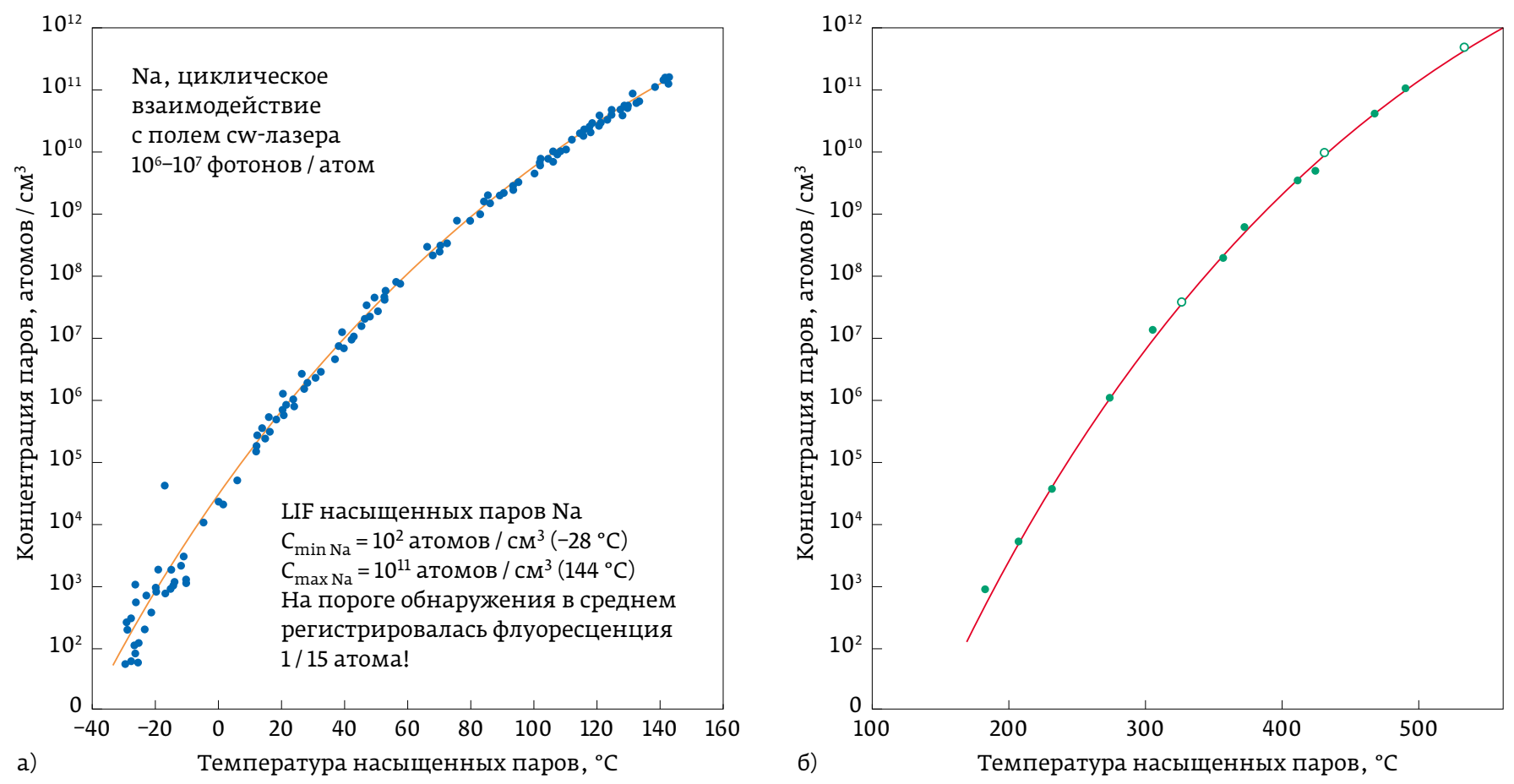

Puc. 1. Графики давления насыщенных паров: $a-\mathrm{Na}$ [1] и 6- Pb [2] 
разнообразные ИСП-спектрометры с эмиссионным и масс-спектральным детектированием аналитов.

Со временем в элементном анализе стало использоваться другое свойство лазеров - их высокая мощность, достаточная для испарения определенной доли образца за счет фокусировки лазерного излучения в малую фокальную область на поверхности твердой пробы. Не вдаваясь в физическую сущность процессов, происходящих в области взаимодействия сфокусированного лазерного излучения с материалом образца, будем называть процесс удаления материала абляцией. Этот термин прижился в аналитической практике и широко используется как в англоязычной, так и в русской научной литературе. Ниже будут кратко рассмотрены два аналитических метода использования лазеров.

\section{Лазерно-индуцированная эмиссионная спектроскопия (ЛИЭС)}

Этот метод получил название в англоязычной литературе - индуцированная лазером спектроскопия пробоя - Laser Induced Breakdown Spectroscopy (LIBS). Термин был введен на заре лазерной эры, когда обнаружили, что сфокусированное излучение импульсного твердотельного лазера вызывает пробой в воздухе с образованием короткоживущей плазмы. Практически одновременно началось использование лазерного излучения для эмиссионного анализа твердых образцов. Лазерное излучение фокусировалось на поверхность мишени, и анализировалась эмиссия лазерной плазмы, возникшей на и над поверхностью образца. Испаренный материал образца атомизируется и ионизируется в высокотемпературной зоне плазмы. В спектре эмиссии такого плазменного сгустка наблюдались как атомные, так и ионные линии макро- и микроэлементов, входящих в состав образца. Этот метод, получивший в русскоязычной литературе термин лазерно-индуцированная эмиссионная спектроскопия (ЛИЭС), сходен с методом искровой эмиссионной спектроскопии, развивавшейся уже не одно десятилетие до изобретения лазеров. Процесс испарения вещества твердой пробы излучением лазера получил название лазерной абляции (ЛА), что является точным переводом англоязычного термина Laser Ablation (LA). Не углубляясь в описание физических процессов, приводящих к удалению вещества из твердой мишени, отмечу, что при использовании импульсных лазеров с длительностью импульса более десятков пикосекунд $\left(10^{-11}\right.$ с) процесс выброса вещества носит, действительно, термический характер. Более интересные физические процессы происходят

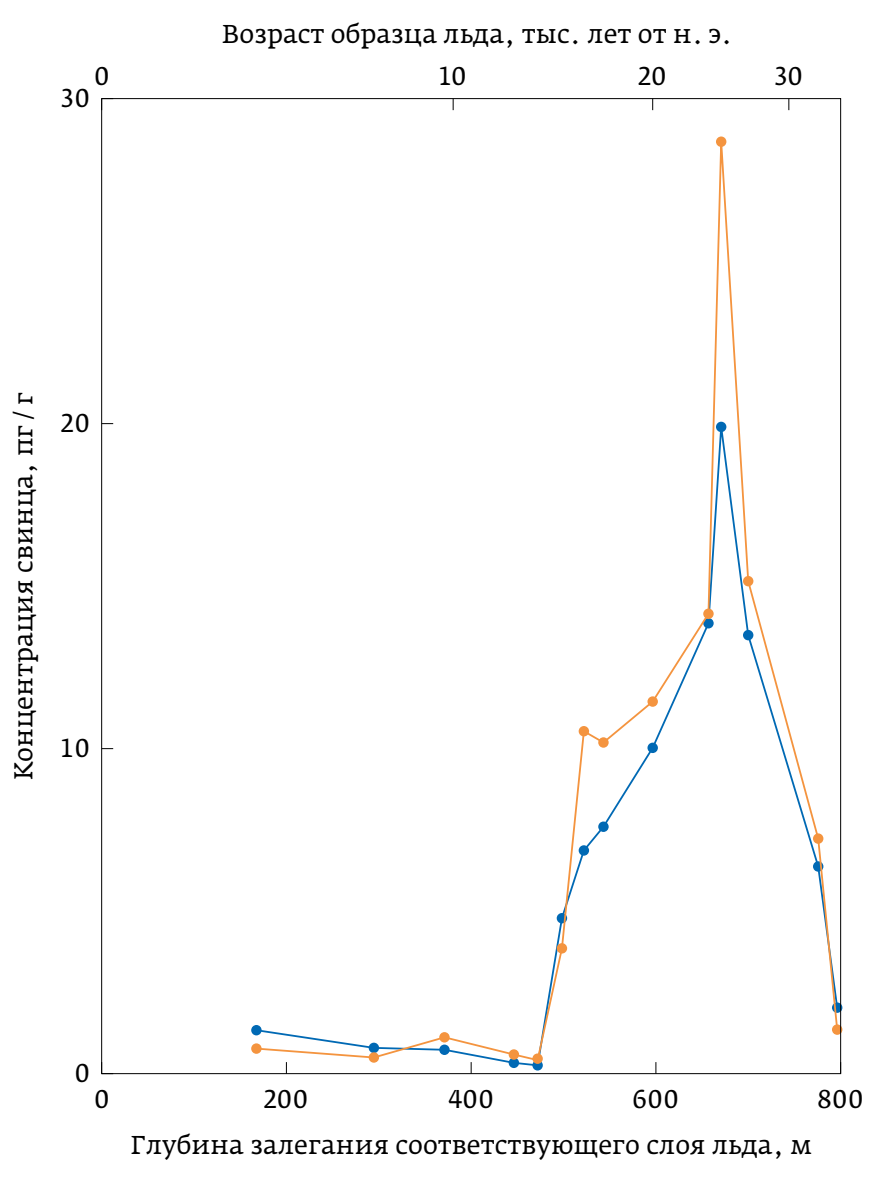

Puc. 2. Профиль содержания свинца в различных слоях льда в скважине Dome C, соответствующих возрасту пиаста [3]

при использовании лазеров с фемтосекундными $\left(10^{-15}\right.$ с) импульсами.

Одна из серьезных проблем ЛИЭС - существенно нестационарный характер лазерной плазмы. Образовавшаяся над поверхностью мишени плазма разлетается и охлаждается очень быстро, поэтому концентрация определяемого элемента, его спектр излучения и степень ионизации в аналитическом объеме зависит от времени. Поэтому при разработке аналитической методики для определения аналитов в твердом образце необходимо оптимизировать следующие параметры: положение зоны наблюдения, из которой излучение плазмы собирается в спектральный прибор, а также временную задержку начала регистрации спектра и длительность строба, то есть время регистрации спектра. Регистрацию эмиссионного линейчатого спектра аналита следует начинать после значительного ослабления интенсивного сплошного спектра тормозного излучения в начальной фазе формирования плазмы. В начальный момент существования плазмы температура в центре достигает (100-150) тыс. К и атомы элементов находятся 


\section{d \\ АНАЛИТИКА экспо}

18-я Международная выставка лабораторного оборудования и химических реактивов

\section{1-24.04.2020}

Москва, МВЦ «Крокус Экспо»
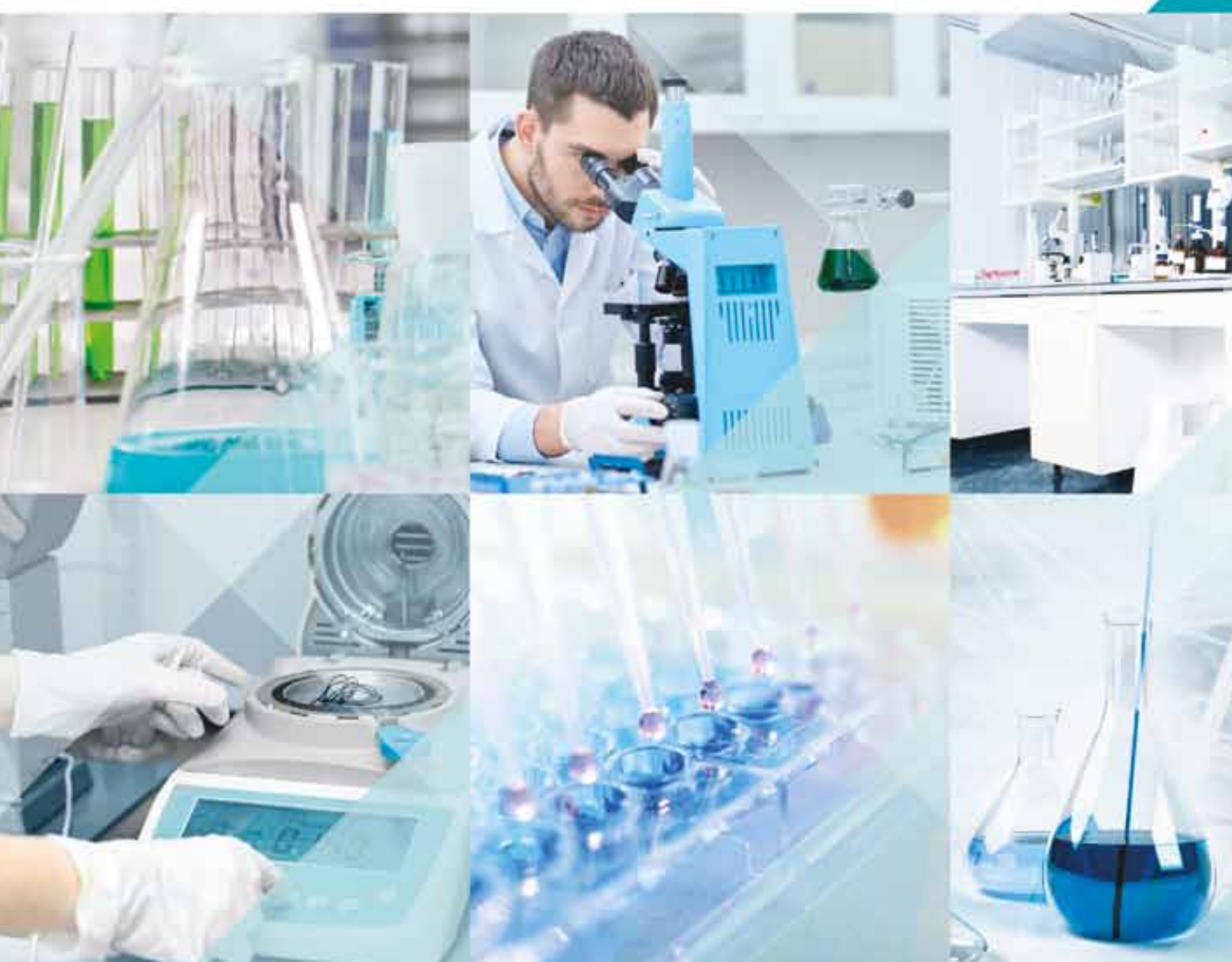

analitikaexpo.com

Забронируйте стенд 


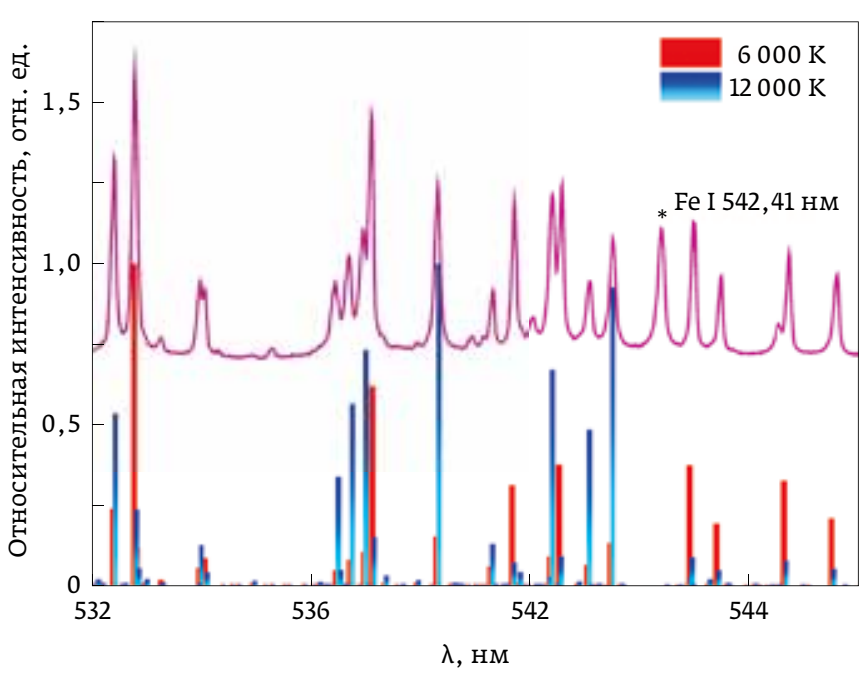

Puc. 3. Экспериментальный спектр чистого железа в окрестности 532-544 нм (верхний) и спектры, рассчитанные для двух температур (внизу) [5]

в ионизованном состоянии. На рис. 3 представлен экспериментальный спектр чистого железа (верхний спектр) и два спектра, симулированных на основании спектроскопических баз данных для двух различных температур (6000 и 12000) K [5]. Видно, что наличие и относительная интенсивность линий аналита (в данном случае железа) в симулированных спектрах существенно зависит от температуры плазмы, а значит, от режима регистрации эмиссионного спектра. Важность этого обстоятельства определяется тем, что существует достаточно ограниченное число стандартных образцов состава (COC), используя которые можно было бы определять концентрацию целевого элемента в анализируемом образце методом внешней градуировки, то есть построением градуировочной кривой по имеющемуся набору СОС.

При отсутствии адекватных СОС определение элементов методом ЛИЭС проводят путем сравнения экспериментального спектра с теоретическим, симулированным на основании спектроскопических баз данных при заданных параметрах плазмы и системы регистрации. Именно поэтому при разработке новой лиэс-методики определения целевых элементов необходимо вначале экспериментально подобрать параметры регистрации, обеспечивающие оптимальное соотношение сигнал/шум, а потом симулировать теоретические спектры для выбранного набора параметров.

Существует еще одна проблема метода ЛИЭС. Состав испаренного материала образца не только меняется во времени в процессе развития плазмы, но и, как правило, не определен. Невозможно оценить долю атомов, ионов, молекул и кластеров в испаренном материале. Это усложняет моделирование процессов над поверхностью образца и зависимость интенсивности линии определяемого элемента от его концентрации в пробе. Сегодня метод ЛИЭС можно признать качественным, или в лучших (простейших) случаях чистых образцов, полуколичественным.

Несмотря на отмеченные проблемы метод ЛИэс активно внедряется в аналитическую практику. Связано это с двумя серьезными обстоятельствами. Во-первых, ЛИЭС, в отличие от идеологически близкого метода искровой эмиссионной спектроскопии, можно использовать для анализа не только проводящих, но и непроводящих образцов. Во-вторых, что более важно, лазерное излучение можно доставлять к образцу с помощью оптических световодов на значительные расстояния. Это достоинство используется в установках, приведенных на рис. 4, 5. На рис. 4 показано ЛИЭС-оборудование для онлайн контроля жидкого шлака. Излучение лазера передается к ковшу с расплавленным и частично затвердевающим шлаком по оптическому световоду и по нему же доставляется излучение эмиссии от расплава к приемнику излучения. Расстояние от поверхности расплава до оптического блока составляет 3,7 м. Методом ЛИЭС измеряются содержания $\mathrm{Si}, \mathrm{Ca}$ и др., и по отношению $\mathrm{SiO}_{2} / \mathrm{CaO}$ определяется зольность шлака. Это позволяет контролировать процесс плавки и резко повышает эффективность получения сплавов с заданным составом. Описанная методика уникальна тем, что реализуется в режиме онлайн без взятия аликвоты расплава.

Еще более экстравагантное применение ЛИэС приведено на рис. 5 , где показано устройство для анализа донных слоев водоема непосредственно на месте (on-site) без подъема образцов на поверхность. Аппаратура ЛиэС закреплена в манипуляторе устройства, глубина погружения аппарата составляла примерно 1000 м. Эти и другие примеры применения методики ЛиЭС в реальных установках приведены в обзоре [6].

Подводя итог, следует отметить основные достоинства и недостатки метода ЛИЭС. К достоинствам следует отнести:

- прямой анализ твердых образцов без стадии предварительного разложения;

- анализ как проводящих, так и непроводящих образцов;

- $\quad$ определение содержания целевого элемента в микронных участках поверхности образца (локальность) за счет фокусировки лазерного излучения в пятно с диаметром в десяток микрон, что особенно ценно при анализе 


\section{Qinalytics vol. 10 Non 2020}
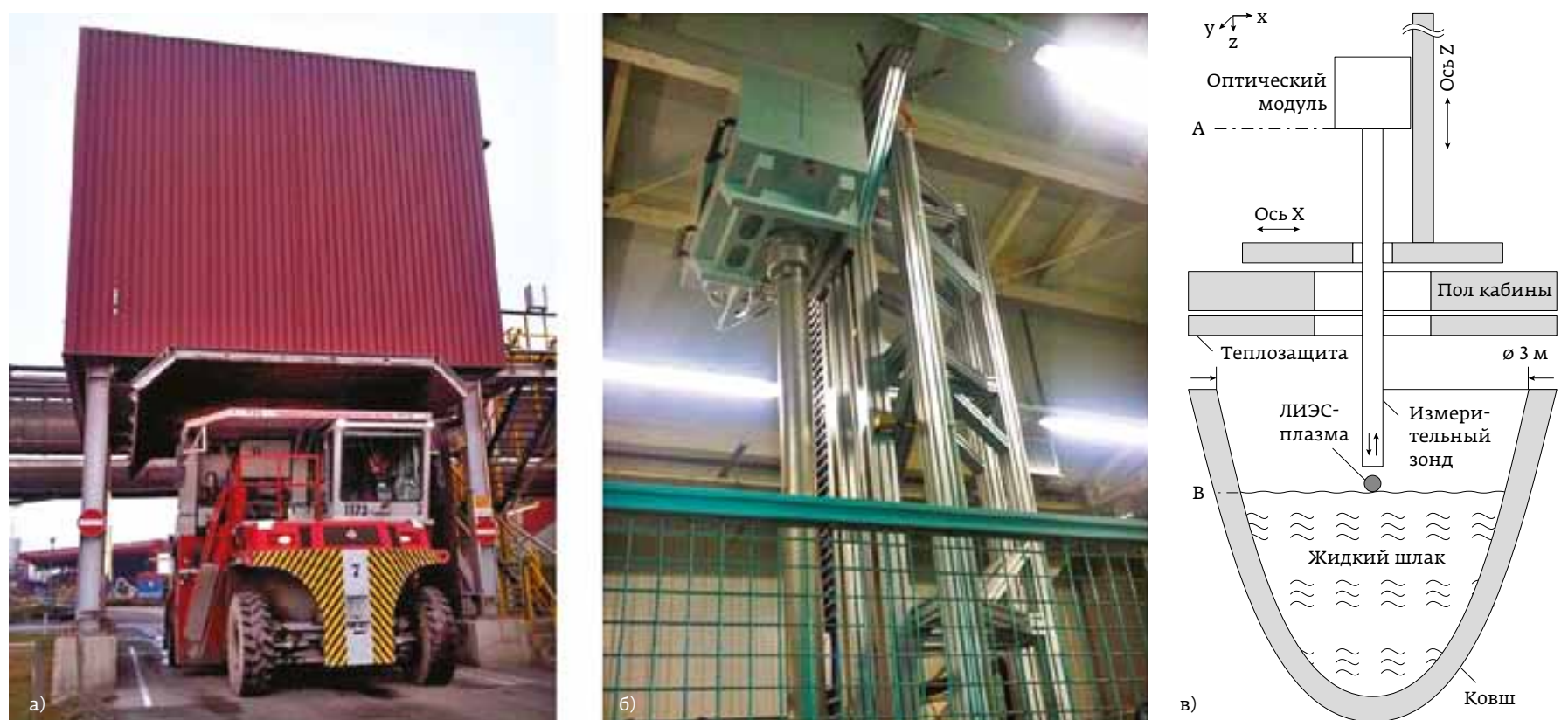

Puс. 4. Внешний вид $(a, 6)$ и оптическая схема (в) ЛИЭС-спектрометра для онлайн диагностики расплава щлака. Устройство размещено на достаточном расстоянии от поверхности, которая находится при температуре 600-1300 C [6]

минералов и пород с локальными включениями ценных целевых элементов;

- для анализа твердого образца не требуется тщательной обработки поверхности (шлифовка, полировка);

- развитие лазерной техники в последние десятилетия обеспечило возможность разработки компактных ЛИЭС-приборов для полевых условий.

К недостаткам можно отнести:

- невысокую чувствительность, определяемую малой массой испаряемого материала; минимальные концентрации определяемого элемента сильно зависят от материала образца, а, следовательно, и массы испаренного матери-

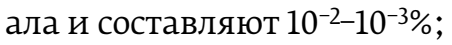

- малую номенклатуру СОС;

- парадоксальным образом локальность может считаться как достоинством, так и недостатком метода, поскольку при анализе неоднородных образцов типа руд, горных пород, минералов возникает проблема представительности результатов анализа;
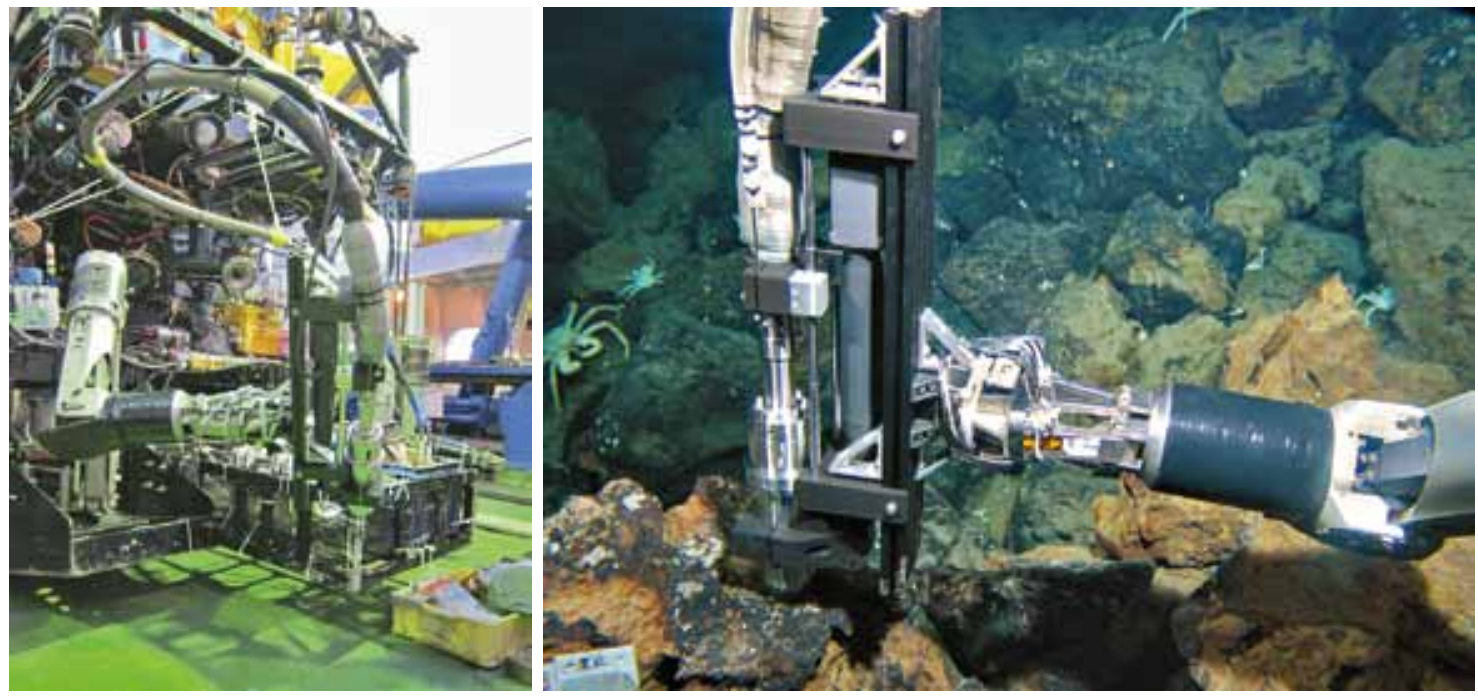

Puc. 5.

Внешний

вид лИЭС-

установки

дия ониайн

анализа донных

материалов под

водой. Глубина

погружения

annapama

$1000 \mathrm{~m} \mathrm{[6]}$ 
- метод является в лучшем случае полуколичественным.

В литературе часто встречаются утверждения о возможности послойного анализа неоднородной твердой матрицы методом ЛиэС. Этот вопрос подробнее рассмотрим ниже.

\section{Комбинированный метод ЛА-ИСП-АЭС / МС}

Более мощным методом прямого анализа твердых образцов является комбинированный метод лазерного испарения пробы и масс-спектрометрии с индуктивно связанной плазмой - ЛА-ИСП-МС. Испаренное вещество образца потоком инертного газа (как правило - гелия) направляется в плазму и регистрируется масс-спектр материала пробы. Общая схема такого спектрометра представлена на рис. 6 [7]. В отличие от ЛИЭС, в создании аналитического сигнала используется бо́льшая часть материала, поскольку мелкие агломераты, кластеры, молекулярные фрагменты испаренной пробы "дожигаются" в высокотемпературной плазме до атомарного состояния и ионизируются. В этой ситуации аналитический сигнал лучше воспроизводится, поскольку практически весь испаренный материал атомизируется и ионизируется в плазме, параметры которой достаточно стабильны. Кроме того, образовавшиеся ионы элементов втягиваются в масс-спектрометр и детектируются со значительно бо́льшей эффективностью, чем эмиссионные фотоны, излученные атомами или ионами элементов пробы в телесный угол 4п. В фотоприемник ЛИЭС попадает лишь часть излученных фотонов
' $\Omega / 4 \pi$, где ' $\Omega$ - угол сбора излучения в эмиссионном спектрометре ЛИЭС.

Максимально полное использование испаренного материала и высокая эффективность регистрации образовавшихся ионов обеспечивают более высокую чувствительность метода ЛА-ИСП-МС по сравнению с методом ЛИэС. Наилучшие пределы обнаружения (ПО) при анализе металлов и сплавов методом ЛА-ИСП-МС достигают $10^{-5}-10^{-7 \%}$ в зависимости от элемента и материала образца. Указанный диапазон ПО соответствует диаметру фокального пятна лазера 100 мкм. При уменьшении диаметра пятна ПО растет в соответствии с уменьшением массы испаренного материала.

Следует отметить еще одно достоинство метода ЛА-ИСП-МС. Поскольку в плазму вдувается сухой материал пробы, уменьшается влияние полиатомных интерференций, которые усложняют интерпретацию результатов в ИСП-МС-анализе растворов.

В обоих методах на базе ЛА серьезной проблемой является так называемое фракционирование, то есть разное соотношение между элементами в твердой пробе и их концентрацией в плазме. Связано это в основном с различием термофизических свойств элементов (теплота плавления и испарения, давление насыщенных паров и т. п.), в результате чего стехиометрия паров испаренного вещества и массивного образца различаются. В последние десятилетия выполнено множество исследований, позволивших понять проблему фракционирования и разработавших методы уменьшения или учета этого эффекта.

Основные области применения ЛА-ИСП-МС - индустрия чистых и сверхчистых материалов, большие региональные лаборатории по контролю состояния

Наблюдение образца:

ПзС-камера / микроскоп
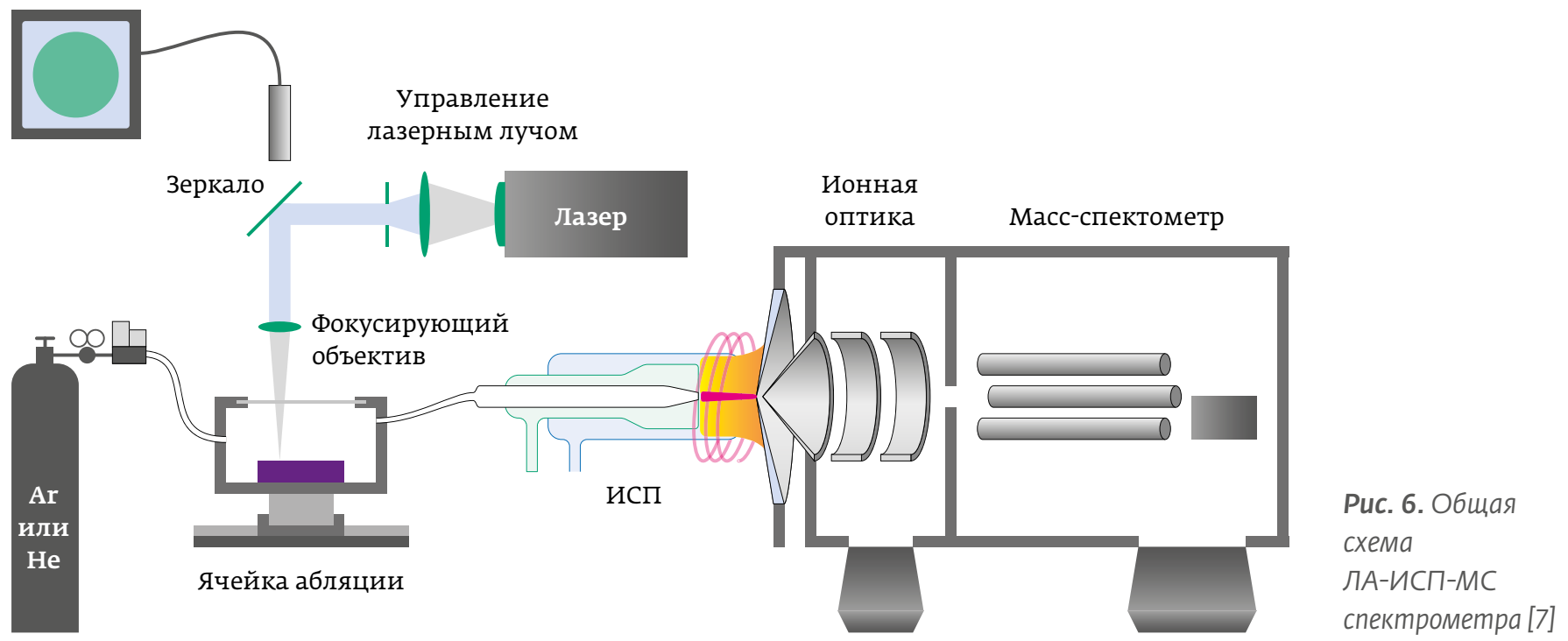
окружающей среды, крупные многопрофильные клиники. Много аналитических работ выполняется в интересах геологии, геохимии, фармацевтики, биохимии. Для анализа биоматериалов высокая чувствительность нужна не столько для определения малых концентраций вещества, сколько для определения низкого содержания аналитов в малом объеме пробы. Один из последних обзоров по методу ЛА-ИСП-МС приведен в [8].

Отдельно следует остановиться на интересном вопросе возможности послойного анализа сложных и композитных конструкционных материалов. На первых порах сформировалось представление, что если мы знаем массу испаренного материала и размер фокального пятна, можно легко рассчитать глубину снятого одним лазерным импульсом слоя образца или непосредственно измерить толщины слоя оптическими методами, и толщина этого слоя даст величину разрешения по глубине. До сих пор подобные утверждения и "данные" встречаются в литературе. На самом деле такое представление весьма наивно. Проблема в том, что в большинстве случаев аналитики, использующие методику ЛА, забывают о неоднородном распределении интенсивности по поперечному сечению лазерного пучка. В лучшем случае такое распределение имеет колоколообразную форму, при которой интенсивность излучения максимальна в центре и спадает к краям. Распределение интенсивности лазера в фокальной области будет иметь такую же форму, за счет чего испарение материала в центре будет значительно сильнее, чем на краях. В результате центр мишени будет "прожигаться" глубже, чем

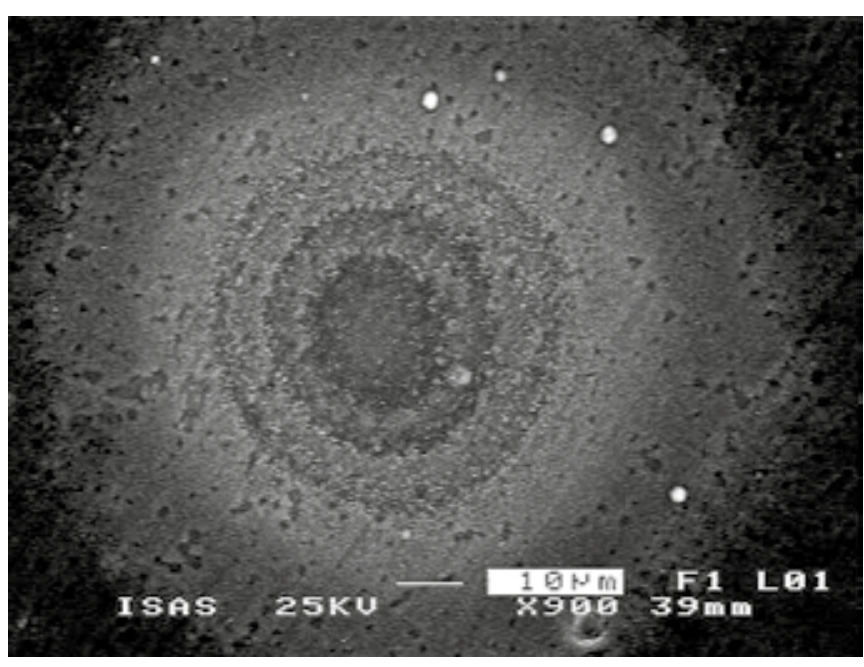

Puc. 7. Профиль лазерного кратера на подложке Fе c TiN / TiAlN-слоями. Распределение интенсивности в поперечном сечении пазерного пучка - гауссовское [9]

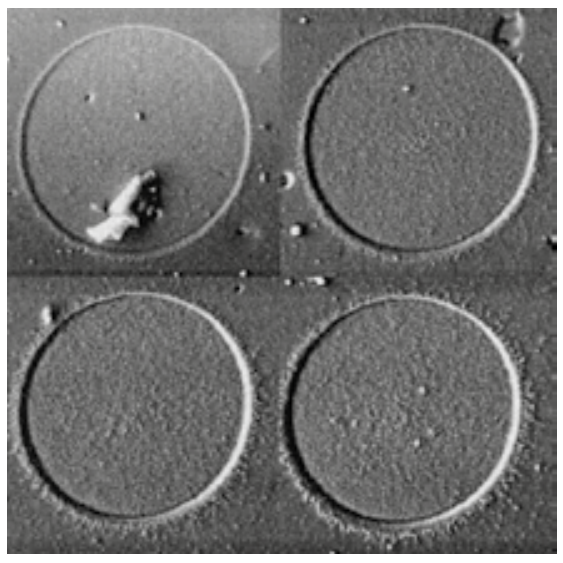

Puc. 8.

Кратеры испаренного мamepuana npu воздействии на мишень пазера с ппоским распределением интенсивности nо поперечному сечению [9]

края, и в такой ситуации говорить о “слое» трудно. Пример такого профиля испаренной мишени представлен на рис. 7, на котором отчетливо видно более глубокое проникновение излучения лазера в центре мишени [9].

Чтобы проводить действительно послойный анализ композиционных материалов, разработаны специальные оптические системы выравнивания интенсивности излучения по поперечному сечению пучка лазера. В результате использования такой оптической системы кратеры на мишени имеют равномерную глубину по сечению (рис. 8) и в таком случае можно действительно говорить о послойном анализе [10]. В дан ${ }^{-}$ ных экспериментах было реализовано разрешение 0,2 мкм за один лазерный импульс.

Подводя итог, следует отметить, что ЛА-ИСП-МС действительно стал мощным методом прямого анализа твердых образцов. По сравнению с ЛИЭС его отличает существенно бо́льшая чувствительность определения вплоть до величин $10^{-7}-10^{-9}$ г/г. При использовании оптической системы, выравнивающей профиль пучка, метод обеспечивает возможность не только локального, но и послойного анализа сложных многокомпонентных материалов. При этом стоимость таких устройств существенно превосходит стоимость ЛИЭС-инструментов и сегодня не просматривается возможность создания портативных и переносных приборов.

\section{Абсорбционная спектроскопия с диодными лазерами}

Существует широкий круг аналитических задач, которые успешно решаются с помощью лазеров совершенно иного типа - перестраиваемых диодных лазеров (ДЛ) видимого и ближнего ИК-диапазона. Описанные в предыдущих разделах импульсные лазеры с мощностью, достаточной для испарения твердой пробы, 
имеют значительные габариты и потребляют киловатты мощности. Полупроводниковые диодные лазеры, напротив, весьма миниатюрны и потребляют сотни ватт электрической мощности. Лазерное излучение в таких полупроводниковых структурах возникает при протекании электрического тока через зону p-nперехода, а длина волны излучения может перестраиваться за счет изменения силы тока. Средняя длина волны излучения ДЛ и область его перестройки зависят от температуры п/п чипа и силы тока. Важнейшей характеристикой дл является скорость перестройки, т. е. изменение длины волны генерации при изменении силы тока. Такая перестройка возможна с частотами до сотен МГц. Известно несколько типов ДЛ, работающих в различных диапазонах и перестраиваемых в пределах разных спектральных интервалов. На рис. 9 приведены: лазерная головка одного из типов ДЛ, а именно лазер с распределенной обратной связью (Distributive Feed Back - DFB), и его перестроечная характеристика, то есть зависимость длины волны и интенсивности излучения от тока инжекции. В конструкции такого ДЛ предусмотрен вывод лазерного излучения в отрезок оптического одномодового световода, из которого излучение может попадать в открытое пространство, либо направляться в другие волоконные световоды через стандартные коннекторы (типа радиочастотных). По таким световодам излучение может транспортироваться на расстояния в сотни и тысячи метров без значительных потерь. Эта характеристика ДЛ обеспечивает их важное преимущество во многих приложениях - возможность проводить диагностику и анализ объектов, расположенных на больших расстояниях от основного аппаратного блока. Параметры ДЛ зависят от типа лазера. Для DFB-лазеров типичными параметрами являются:
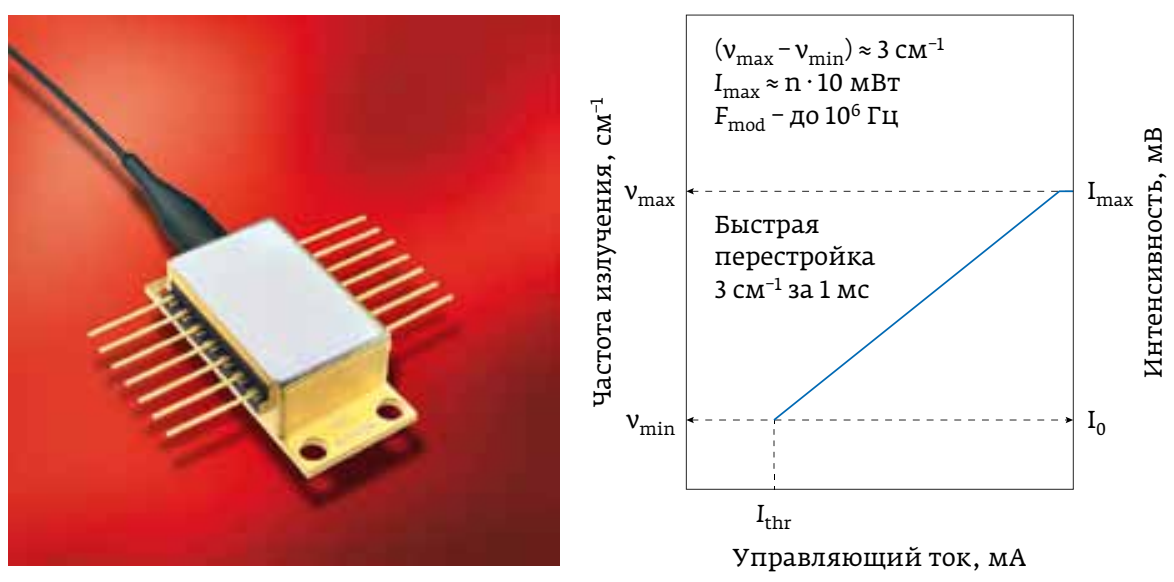

Puc. 9. DFB-диодный лазер с выводом излучения в отрезок одномодового световода (слева) и перестроечная характеристика мощность непрерывного излучения (1-50) мВт, диапазон быстрой перестройки током при фиксированной температуре диода (1-5) см$^{-1}$, диапазон перестройки температурой (1-100) $\mathrm{cm}^{-1}$.

Если ранее обсуждался элементный анализ методами лазерной спектроскопии, то ДЛ используются преимущественно для исследования и детектирования молекул. Приведем несколько примеров использования ДЛ.

Разработаны и установлены диодные лазерные абсорбционные спектрометры (ДЛАС) на предприятии по производству чистых газов и газовых смесей [11]. Это оборудование встроено в производственный цикл очистки газов.

Разработан вариант ДЛАС-спектрометра для скрининговой диагностики здоровья пациента по выдыхаемому воздуху [12]. Биомаркерами состояния служили ${ }^{12} \mathrm{CO}_{2},{ }^{13} \mathrm{CO}_{2}, \mathrm{CH}_{4}, \mathrm{H}_{2} \mathrm{~S}, \mathrm{NH}_{3}$ и $\mathrm{H}_{2} \mathrm{O}$. Этот трехканальный спектроанализатор позволяет одновременно определять концентрации биомаркеров на длинах волн излучения 1,$60 ; 1,51 ; 1,65$ мкм. Для увеличения точности измерения концентраций выдыхаемый пациентом воздух попадал в многопроходную оптическую кювету с базой 30 см и полной длиной оптического пути 26 м. Ученые ИОФ РАН совместно с сотрудниками РГМУ им. Н. И. Пирогова и ГКБ № 12 им. В.М. Буянова проводили клинико-физиологические испытания прибора с целью определения границ "нормы" и нахождения корреляций между отклонениями от "нормы" и наличием тех или иных заболеваний. Сравнивали концентрации аммиака в выдыхаемом воздухе у людей относительно здоровых и с язвенной болезнью в фазе ремиссии и обострения. Обнаружено, что у здоровых людей и больных в состоянии ремиссии содержание аммиака в выдыхаемом воздухе в 2-3 раза ниже, чем у больных язвенной болезнью в стадии обострения.

Разработан бортовой вариант ДЛАС-спектрометра для измерений концентраций парниковых газов на различных высотах от поверхности Земли. Спектрометр устанавливали непосредственно на специально оборудованном самолете Росгидромета, а измерения проводили непосредственно в полете [13].

Большая область применения дл связана с измерением параметров горячих зон, например, зон горения в двигателях внутреннего сгорания, в до/сверхзвуковых потоках смешивающихся газов (топлива 


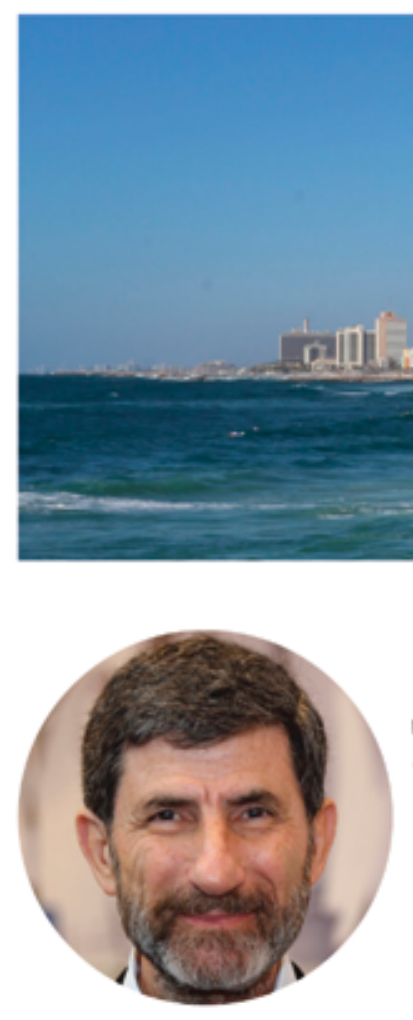

\section{Дорогие коллеги,}

от имени международного консультативного комитета семинара приглашаю вас принять участие в этом мероприятии, а также в 24-й конференцией и выставкой Isranalytica, 19-20 янв. 2021, Тель Авив, Израиль.

Основная цель семинара - обсуждение опыта химиков-аналитиков, метрологов и специалистов по качеству в области валидации методов, количественной оценки неопределенности измерений, рисков в оценке соответствия из-за неопределенности измерений, проверки квалификации, справочных материалов и обработки лабораторных данных в фармацевтике, промышленности, анализе продуктов питания, анализе окружающей среды, криминалистике и других областях.

\section{Это обсуждение будет включать следующие темы:}

- корреляция результатов измерений-анализа-испытаний;

- влияние баланса масс и других особенностей результатов испытаний на неопределенность результатов испытаний и риски в оценке соответствия;

- оценка рисков управления химической аналитической лабораторией в соответствии с требованиями аккредитации.

Семинар организован Израильским обществом аналитической химии (IACS) с участием Израильского подразделения по аккредитации лабораторий (ISRAC) в кооперации с Международной организацией теоретической и прикладной химии (IUPAC) и Международной организацией по прослеживаемости в аналитической химии (CITAC), при технической поддержке компании Bioforum Ltd. Страница вебсайта семинара будет размещена на www.isranalytica.com (см. также https://iupac.org/event/metrology-quality-and-chemometrics/).

Тезисы ваших лекций или постеров (до 300 слов) и краткую биографию (до 100 слов) присылайте до 15 сентября 2020 года Илье Кусельману - Ilya Kuselman, ilya.kuselman@gmail.com.

Все организационные вопросы, касающиеся участия, виз, гостинниц, и т.д., направляйте г-же Реут Лазар - Ms. Reut Lazar, reutl@bioforum.co.il (рабочий язык - английский). 

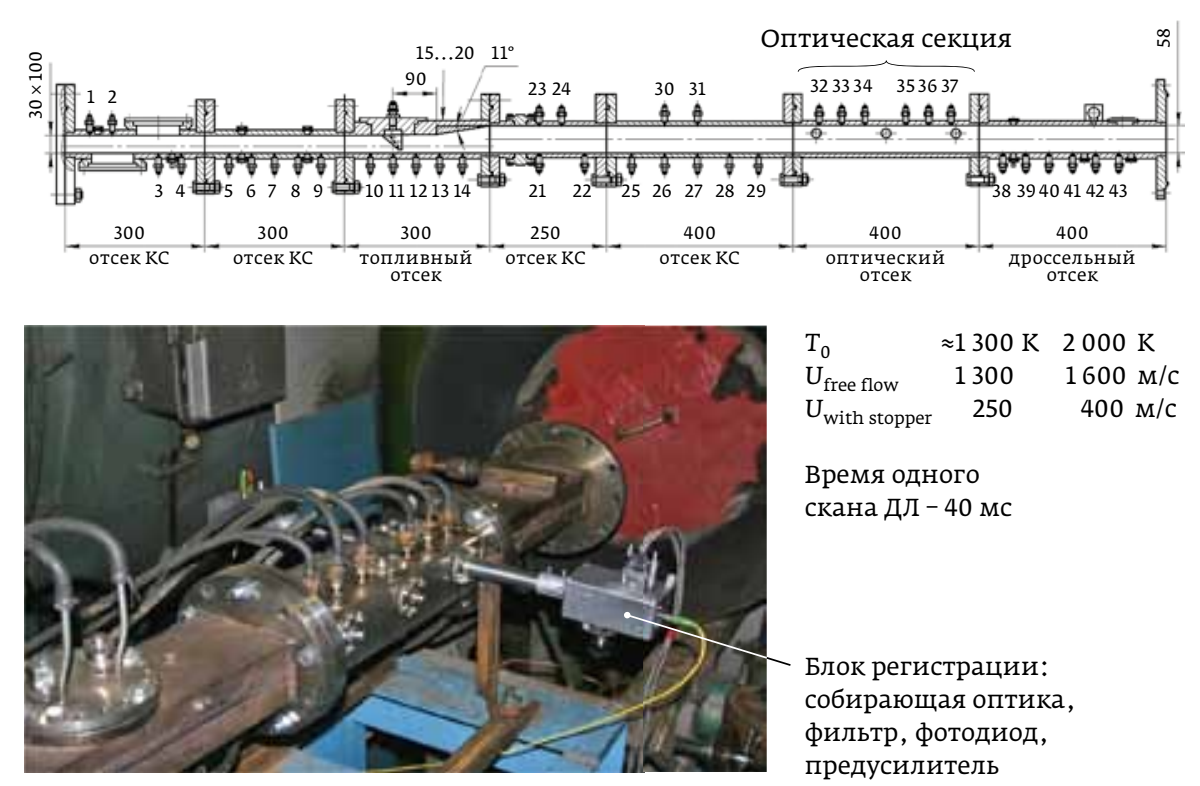

$$
\begin{array}{lcr}
\mathrm{T}_{0} & \approx 1300 \mathrm{~K} & 2000 \mathrm{~K} \\
\mathrm{U}_{\text {free flow }} & 1300 & 1600 \mathrm{M} / \mathrm{c} \\
\mathrm{U}_{\text {with stopper }} & 250 & 400 \mathrm{M} / \mathrm{c}
\end{array}
$$

Время одного

скана ДЛ - 40 мс

Блок регистрации: собирающая оптика, фильтр, фотодиод, предусилитель

Puc. 10. Блок-схема испытательного стенда Т-131 в ЦАГИ и вид оптического узла с укрепленными ДЛАС-спектрометрами на входном и выходном фианцах макета [14]

и окислителя), зон истечения газов из реактивных двигателей и т.п. В таких исследованиях измеряют кинетическую температуру зоны, концентрацию важных молекулярных компонентов горения (вода, углеводороды, окислы углерода и азота и т. п.), полное давление газовой смеси в зоне горения. Важно отметить, что в этих исследованиях нельзя в диагностируемый поток вводить традиционные датчики давления и термопары, поскольку введение любого предмета непосредственно в поток существенно искажает его характеристики и приводит к неправильным результатам измерений. В этой ситуации диагностика бесконтактными методами лазерной спектроскопии является единственной альтернативой. Наиболее часто бесконтактную диагностику горячих зон осуществляют двумя методами: ДЛАС и когерентной антистоксовской резонансной спектроскопией (КАРС).

Оба метода основаны на предположении о термодинамическом равновесии в зоне измерения, которое выполняется для давления в смеси больше 0,1 атм. и временах больше миллисекунд. В условиях термодинамического равновесия распределение населенностей различных уровней молекул подчиняется закону Больцмана, а отношение интенсивностей спектральных линий поглощения одной молекулы зависит только от температуры среды. В методе длАС длина волны Дл быстро перестраивается в спектральном диапазоне $-3 \mathrm{~cm}^{-1}$, в котором расположены сильные линии поглощения тестовой молекулы. Измеряется интенсивность прошедшего через зондируемый объем пучка лазера, вычисляются интенсивности линий поглощения молекулы и по их отношению определяется температура среды, а из полного поглощения на длине зондирования определяется концентрация молекул тестового вещества [14].

При диагностике газовой среды методом ДЛАС обычно зондируются простые молекулы. В качестве тестовых используются либо молекулы, естественным образом возникающие в исследуемом объеме $\left(\mathrm{H}_{2} \mathrm{O}, \mathrm{CO}_{2}, \mathrm{CO}, \mathrm{C}_{\mathrm{n}} \mathrm{H}_{\mathrm{m}}\right)$, либо те, которые добавляют искусственно как маркеры. Наиболее часто в качестве тестовой молекулы выбирается молекула воды, поскольку $\mathrm{H}_{2} \mathrm{O}$ является конечным продуктом сгорания углеводородных компонентов топлива. По концентрации паров воды на финальных стадиях процесса горения судят об эффективности сгорания топлива.

Важным этапом получения информации о горячей зоне является сопоставление экспериментальных спектров поглощения с теоретическими, симулированными на основании спектроскопических баз данных. Теоретические спектры симулируются для набора значений температуры и давления среды, а искомые величины определяются по минимуму разности между экспериментальным и теоретическим спектрами. В Институте спектроскопии РАН разработано несколько макетов ДЛАС-спектрометров для диагностики различных экспериментальных установок. На рис. 10 показан фрагмент экспериментального испытательного стенда в Центральном аэрогидродинамическом институте (ЦАГИ). На камере сгорания с оптическими окошками для ввода и вывода лазерного излучения укреплены блоки ДЛАС, которые обеспечивают формирование зондирующего луча дл и регистрацию прошедшего через камеру излучения. Поскольку работа стенда сопровождается сильнейшими акустическими и электрическими помехами, чувствительную измерительную аппаратуру размещали в удаленном помещении, а излучение лазера и сигналы с фотоприемников передавали по световодам и электрическим кабелям на расстояние 30 м. Результаты измерения температуры нагретого газа приведены на рис. 11. 3D-образы представляют совокупность отдельных спектров (ось X) поглощения 
в окрестностях линий 1,392 и 1,343 см-1, зарегистрированных в последовательных сканах длин волн двух ДЛ (ось Y). Длительность каждого скана (ось X) составляла примерно 1 мс, а полное время регистрации процесса 5 с (ось Y). Ступенька на картинке соответствует резкому изменению параметров в горячем потоке (скачок Т и давления).

\section{Использование лазеров}

\section{в уникальных экспериментах}

Как уже отмечалось, методы резонансной лазерной спектроскопии были вытеснены из элементного анализа многоэлементными методами на основе ИСП. Тем не менее, методы лазерной флуоресценции и поглощения применяются на уникальных установках в различных международных научных центрах. В качестве примера можно привести эксперименты в ЦЕРН по производству и детектированию редких изотопов на установке ISOLDE. Схема этого эксперимента приведена на рис. 12. Источниками резонансного излучения в этих экспериментах были лазеры на красителях, возбуждаемые излучением мощного лазера на парах меди. Мощным протонным пучком производились редкие атомы, которые резонансно ионизовались излучением трех лазеров на красителях, настроенных на разные переходы в атоме. За счет такой каскадной ионизации селективно ионизовались только атомы исследуемого элемента. Образовавшиеся ионы анализировали в масс-сепараторе. Отметим, что излучение лазеров на красителях транспортировалось до зоны нейтронного пучка на расстояние больше 10 м. Такие исследования возможны только с когерентным лазерным излучением.

Подводя итог, можно сказать, что сегодня в широкую аналитическую практику лазеры вошли в основном как источники мощного импульсного излучения, обеспечивающие испарение образцов при прямом анализе твердых материалов. Метод ЛИЭс успешно коммерциализуется и уже используется в промышленных установках. Являясь в лучшем случае полуколичественным, он, тем не менее, позволяет быстро получать важную информацию об анализируемом образце.

Значительно более высокими метрологическими характеристиками обладает метод ЛА-ИСП-АЭС/MC. Дожигание испаренного материала твердой мишени в плазме обеспечивает значительно более воспроизводимые режимы измерения и более высокую чувствительность определения широкого набора элементов. В последние годы успешно разрабатывается методика ЛА-ИСП-МС анализа микро- и наночастиц, позволяющая характеризовать отдельные частицы испаренного материала. Высокая чувствительность определения малого объема пробы особенно востребована при анализе биоматериалов.
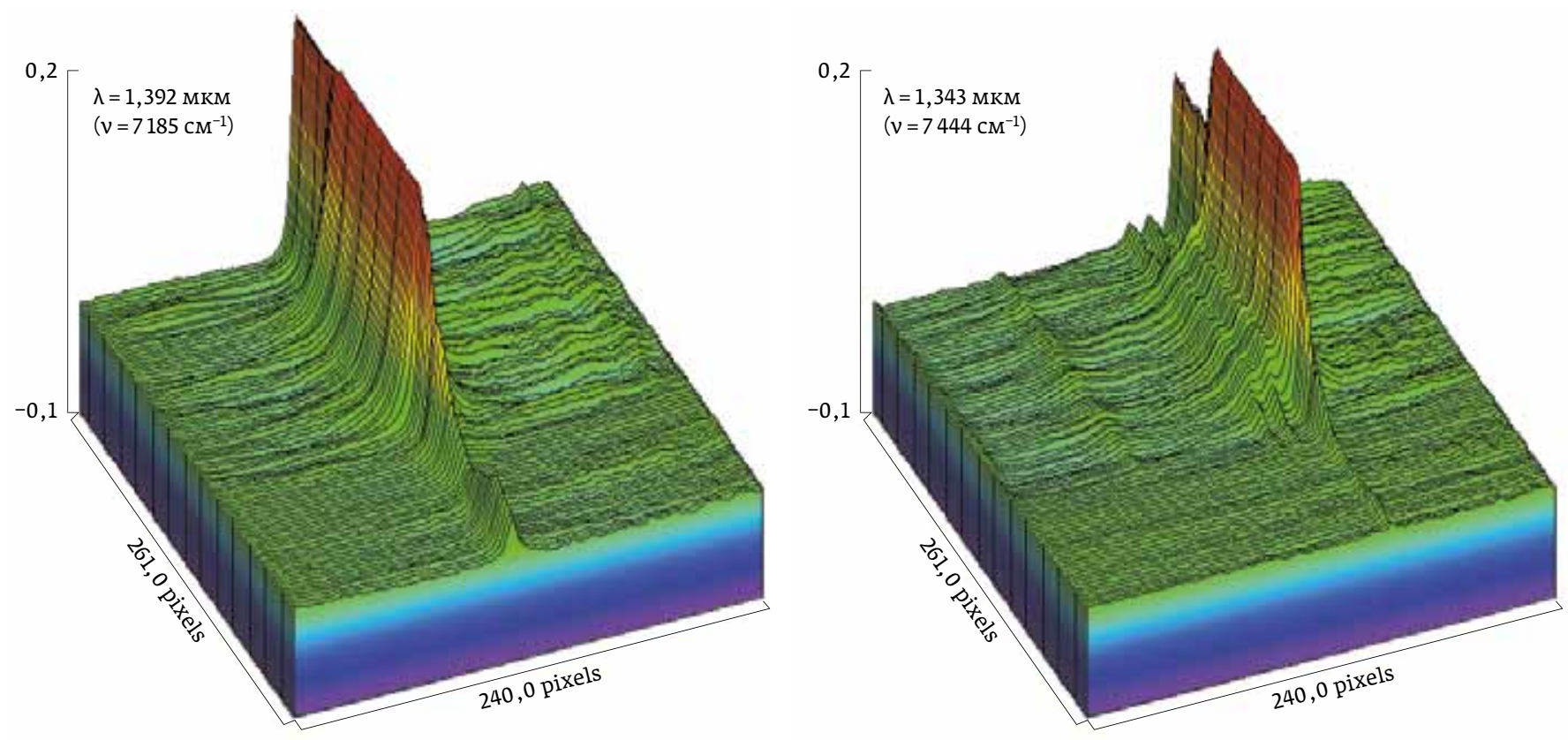

Puc. 11. 3D-профили температуры в одном пуске испытательного стенда. По оси Х представлены спектры поглощения молекул $\mathrm{H}_{2} \mathrm{O}$ в спектральных областях 1,392 $\mathrm{cm}^{-1}$ и 1,343 см-1. Ширины сканов в окрестностях каждой линии примерно $3 \mathrm{~cm}^{-1}$. Последовательные сканы сгруппированы вдоль оси Ү. Полное время регистрации всех сканов примерно 5 с [14] 


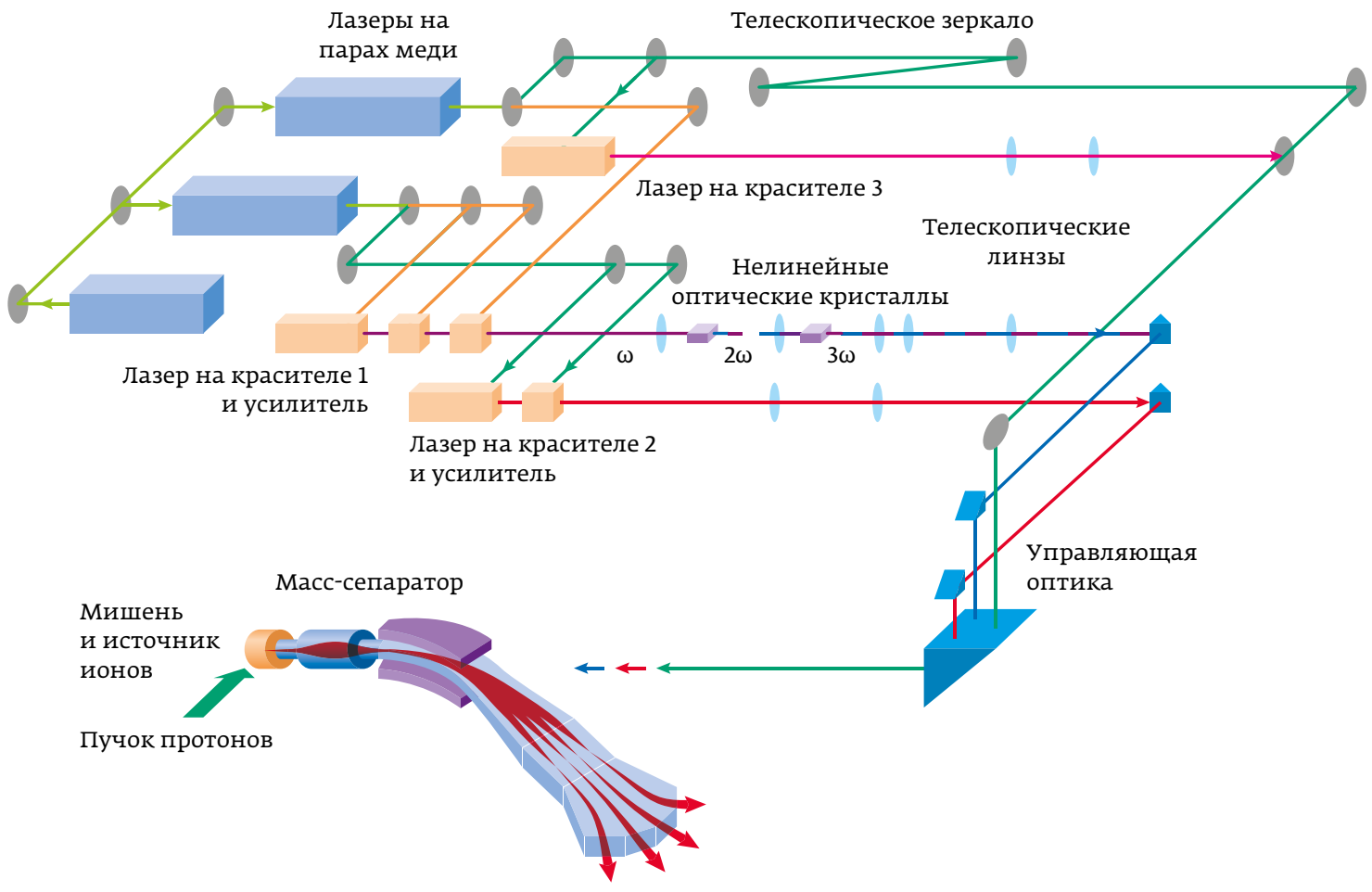

Puc. 12. Много-

канальный

пазерный источ-

ник ионизации

исследуемых

редких изотопов

на установке

RILIS (Resonance

Ionization Laser

Ion Source)

ISOLDE в ЦЕРH.

Ионизация

осуществлялась

излучением

трех лазеров

с длинами волн, nepecmpau-

ваемыми

в диапазонах

530-850 нм,

265-425 нм,

u 213-265 HM

Успешно развиваются методы дистанционного анализа и диагностики горячих и опасных зон с использованием перестраиваемых диодных лазеров. Метод абсорбционной спектроскопии с диодными лазерами позволяет бесконтактно определять важные параметры газовых сред, такие как температура, полное давление в среде, концентрацию отдельных компонентов. Такая диагностика необходима для разработки разнообразных двигателей нового поколения.

\section{Литература / References}

1. Fairbank W. M., Hänsen T. W., \& Schawlow A.L. Absolute measurement of very low sodium-vapor densities using laser resonance fluorescence. Journal of the Optical Society of America, 1975. V. 65. No. 2. 199. doi:10.1364/josa.65.000199.

2. Bolshov M. A., Zybin A.V., Koloshnikov V.G., Vasnetsov M.V. Detection of extremely low lead concentrations by laser atomic fluorescence spectrometry Spectrochimica ActaB. 1981. V. 36B, No. 4, pp. 345-350. DOI 10.1016/0584-8547(81)80035-3.

3. Bol'shov M. A., Boutron C. F., \& Zybin A.V. Determination of lead in Antarctic ice at the picogram-per-gram level by laser atomic fluorescence spectrometry. Analytical Chemistry. 1989. V. 61. No. 15. P. 1758-1762. doi:10.1021/ac00190a033.

4. Boutron C. F., Görlach U., Candelone J.P., Bolshov M. A. and Delmas R.J. Decrease in anthropogenic lead, cadmium and zinc in Greenland snows since the late 1960s. Nature. 1991. 353153-155 DOI 10.1038/353153a0

5. Zaytsev S.M., Popov A.M., Labutin T. A. Stationary model of laser-induced plasma: Critical evaluation and applications. Spectrochimica Acta Part B. 2019. V. 158. Art.No. 105632 DOI:10.1016/j.sab.2019.06.002.

6. Noll R., Fricke-Begemann C., Brunk M., Connemann S., Meinhardt C., Scharun M., Sturm V., Makowe J., Gehlen C. Laser-induced breakdown spectroscopy expands into industrial applications. Spectrochimica Acta. Part B. 2014. V.93. P. 41-51/7.
7. Gunther D., Hattendorf B. Solid sample analysis using laser ablation inductively coupled plasma mass spectrometry. Trends in Analytical Chemistry. 2005. V. 24, No. 3. P. 255-265.

8. Harlaux M., Borovinskaya O., Frick D. et al. Capabilities of sequential and quasi-simultaneous LA-ICPMS for the multi-element analysis of small quantity of liquids (pl to $\mathrm{nl}$ ): insights from fluid inclusion analysis. Journal of Analytical Atomic Spectrometry. 2015., V. 30. P. 1945-1969.

9. Margetic V., Bolshov M., Stockhaus A., Niemax K. and Hergenroder R. Depth profiling of multi-layer samples using femtosecond laser ablation. J. Anal. At. Spectrom. 2001. V. 16. P. 616-621.

10. Gunther D.; Frischknecht R.; Heinricha Ch.; Kahlert H-J. Capabilities of an Argon Fluoride $193 \mathrm{~nm}$ Excimer Laser for Laser Ablation Inductively Coupled Plasma Mass Spectrometry Microanalysis of Geological Materials. J Anal. At. Spectrom. 1997. V. 12. P. 939-944.

11. Надеждинский А.И., Понуровский Я. Я. Работы по аналитическому использованию диодной лазерной спектроскопии в Институте Общей Физики РАН. ЖАХ. 2018. Том 73. № 2, С. 153-158. Nadezhdinsky A.I., Ponurovskii Y.Y. Works on the analytical use of diode laser spectroscopy in the General Physics Institute RAS. Journal of Analytical Chemistry. 2018. V. 73. No.2. P. 153-158.

12. Karabinenko A. A., Nadezhdinsky A. I., Ponurovsky Ya. Ya., Presnova E. D., Nikitin I. G. Phenomena detected by the method of diode laser spectrometry of gaseous metabolites of the exhaled air of a human being. Wschodnioeuropejskie Czasopismo Naukowe. 2018. V. 29. No 1. P. 30.

13. Nadezhdinsky A.I., Shapovalov Y.P., Ponurovskii Y.Y. et al. Preliminary results of an aircraft system based on near-IR diode lasers for continuous measurements of the concentration of methane, carbon dioxide, water and its isotopes. Appl.Phys. B. 2012. V. 109. P_. 505-510.

14. Лигер В.В., Курицын Ю.А., Мироненко В.Р., Большов М.А., Понуровский Я.Я., Колесников О.М. Измерение параметров нестационарных газовых потоков методом диодной лазерной абсорбционной спектроскопии в условиях высоких температур и давлений. Теплофизика высоких температур. 2018. Т. 56. С. 92-103. Liger V.V., Kuritsyn Y.A., Mironenko V.R., Bolshov M.A., Ponurovskii Y.Y., Kolesnikov O.M. Measurement of Non-Stationary Gas Flow Parameters Using Diode Laser Absorption Spectroscopy at High Temperatures and Pressures. High Temperature. 2018. V. 56. N 1. P. 98-108. doi 10.1134/S0018151X18010108. 
16-Й МОСКОВСКИЙ МЕЖДУНАРОДНЫЙ ИННОВАЦИОННЫЙ ФОРУМ ТОЧНЫЕ ИЗМЕРЕНИЯ ОСНОВА КАЧЕСТВА И БЕЗОПАСНОСТИ

2-4 июня 2020 г., Москва, ВДНХ, павильон 75 $16^{\text {th }}$ MOSCOW INTERNATIONAL INNOVATION FORUM ACCURATE MEASUREMENTS THE BASIS FOR QUALITY AND SAFETY June 2-4, 2020, Moscow, VDNH, Exhibition hall 75

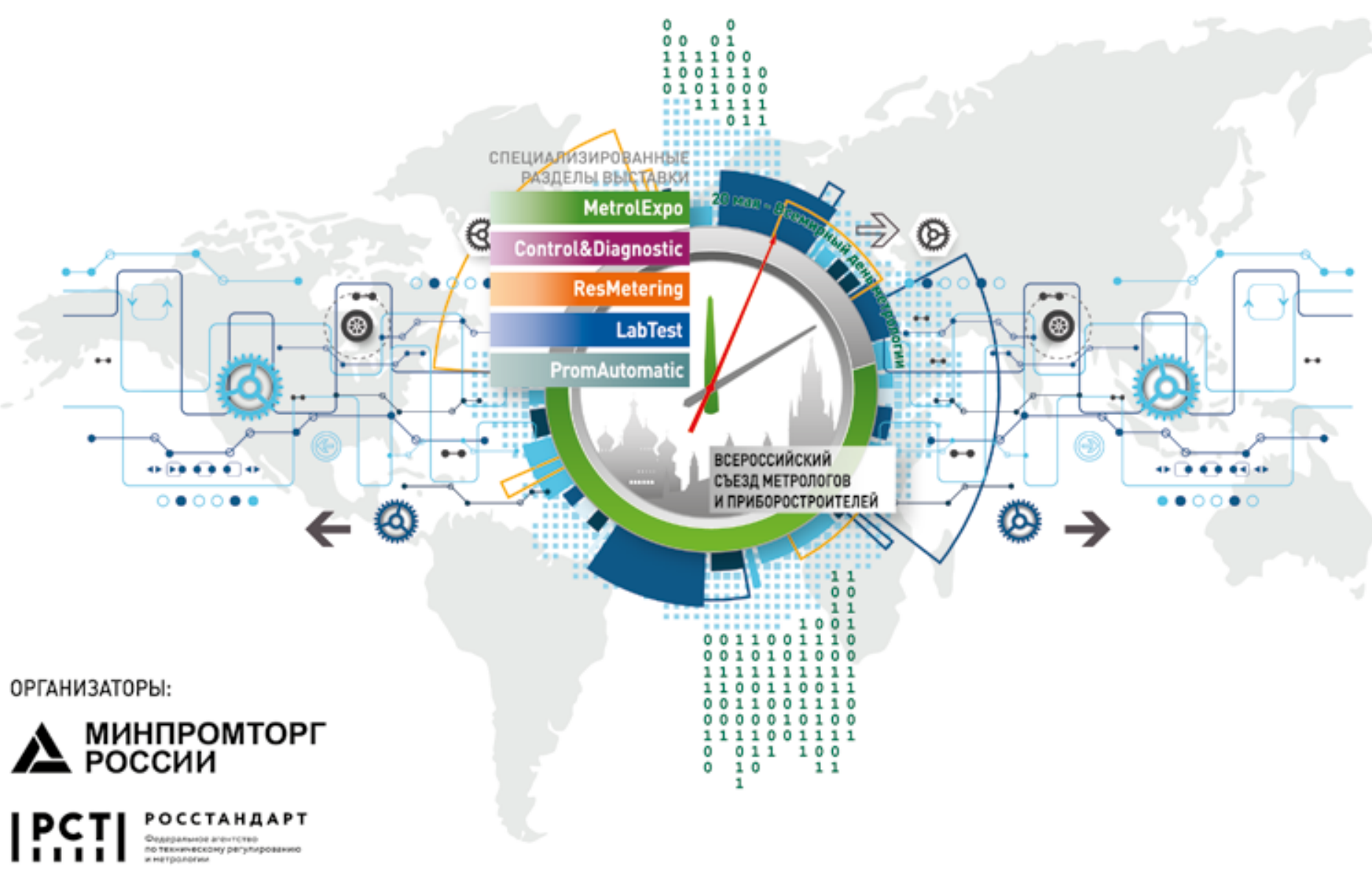

СПЕЦИАЛИЗИРОВАННЫЕ РАЗДЕЛЫ ВЫСТАВКИ METROLEXPO

МЕТРОЛОГИЯ, ИЗМЕРЕНИЯ И ИСПЫТАНИЯ

CONTROL\&DIAGNOSTIC

КОНТРОЛЬ И ДИАГНОСТИКА

\section{LABTEST}

ЛАБОРАТОРНЫЕ ИСПЫТАНИЯ

PROMAUTOMATIC

ПРОМЫШЛЕННАЯ АВТОМАТИЗАЦИЯ

\section{RESMETERING}

УЧЕТ ЭНЕРГОРЕСУРСОВ

WEIGHT SALON

ВЕСОВОЙ САЛОН
ФОРУМ 2019 г. (ЦИФРЫ И ФАКТЫ):

Участники - 256 компаний из 24 стран мира Посетители - 4870 специалистов Площадь экспозиции - $6500 \mathrm{~m}^{2}$ Приборы и оборудование - более 2000 ед. Докладов и презентаций - 68 чел. Участников съезда - 1100 чел.

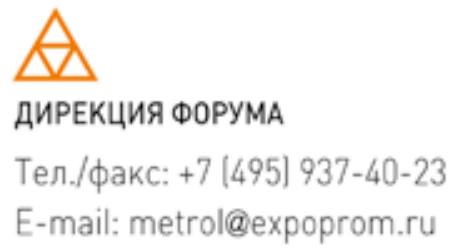

